\title{
Study on Freezing Disaster Mechanism and Prevention Strategy of Geotechnical Engineering in Cold Region
}

\author{
Yao Xu, Ping Hu \\ School of Civil Engineering, University of Jinan, Jinan, Shandong, China, 250022
}

Keywords: Freezing Disaster Mechanism, Prevention Strategy, Geotechnical Engineering

\begin{abstract}
The freezing disaster is one of the main disasters in the cold geotechnical engineering. Due to the complexity of geotechnical engineering problems, many problems can not be evaluated by the accurate mathematical model. In this paper, from the point of view of system theory, the basic characteristics and forecasting model of freezing and thawing disaster in cold area are studied by system analysis method. On the basis of the study of disaster and freezing disaster, the significance of introducing the concept of freezing disaster is expounded. Based on the system theory, the necessity of studying the freezing disaster by using the system view is discussed, and two kinds of freezing disaster system.
\end{abstract}

\section{Introduction}

China is one of the most serious and most serious geotechnical disasters. China's vast territory, the geological environment is complex, the western region rich in natural resources, but the ecological environment is very fragile, geotechnical disasters and more types, wide distribution, damage, landslides, ground subsidence, ground fissures, special soil and other disasters are serious The impact of the geotechnical engineering carried out, threatening the safety of people's lives and property, restricting the development of the national economy. Therefore, it is necessary to study the distribution law of geotechnical engineering disaster, summarize the law and characteristics of the disaster, and then understand the nature of the disaster, find disaster reduction and disaster prevention measures, and provide scientific basis for the strategic decision and national economic construction of the western development.

Frozen soil is a special kind of negative or zero temperature and contains ice soil or rock. Frozen soils are usually divided into permafrost and seasonal permafrost according to freezing time. Seasonal permafrost refers to the soil that is frozen in winter and melted in summer. The frozen soil, which lasts for more than two years, is called permafrost. Permafrost: mainly distributed in the Qinghai-Tibet Plateau, Pamirs, western mountains (including Qilian Mountains, Altun Mountains, Tianshan Mountains, West Junggar Mountains and Altai Mountains), the size of the Xing'an Mountains and some eastern mountains. China's seasonal frozen soil distribution is quite extensive, all over the Yangtze River Basin more than 10 provinces north. The southern boundary roughly from the southeastern part of Yunnan Province to the northeast along the Hengduan Mountains and the Kala Mountains slope foot, the south of the mountain to the southeast of the Sichuan Basin, and from Hunan Province, near the fruit to the northeast extension , Until near Lianyungang, Jiangsu Province. In addition, in the Dabie Mountains, Laiyang Mountains and Yushan at the top there are sporadic distribution. The southern boundary of the instantaneous permafrost is roughly consistent with the Tropic of Cancer. This line is to the south, in addition to mountain, the general no frozen soil. The distribution pattern of frozen soil is closely related to the annual mean temperature, and the general pattern of permafrost distribution in China shows obvious zonal and high degree of zoning. From north to south, with the latitude, the permafrost type gradually gradient: large continuous permafrost, discontinuous permafrost, seasonal frozen soil, instantaneous permafrost and no frozen soil, this latitude zonation in the eastern region is particularly evident The

\section{Analysis of Freezing Disaster Mechanism}

Soil frost heave must have the following conditions: soil with frost heights: initial moisture and 
external water supply; suitable freezing conditions and time. These three conditions are indispensable. People use certain measures to weaken one of the conditions can inhibit the frost heave, to achieve the purpose of anti-freeze injury. Soil frost heaving process is basically carried out according to the following stages:

The crystallization of water, like any liquid crystal, can only be carried out when there is a crystallization center in the liquid. The crystallization center is present in the cooled liquid in a variety of mechanical inclusions or molecular undulation surface, is the temperature than the liquid crystallization temperature is lower when the formation. The degree of subcooling is related to the nature of the substance. Any water under natural conditions contains a certain amount of impurities which may become the center of the crystal. Soil can have several types of water at the same time. The strong adsorption of water on the surface of the soil particles is difficult to form ice crystal frame, and the mobility of large capillary water molecules tend to be composed of ice crystal frame. Soil particles are also the crystallization nuclei that promote the crystallization of water. As the volume of water decreases, the degree of water cooling increases, and the probability of crystal formation is reduced accordingly.

When the temperature falls below the freezing temperature of the soil, a very gentle isotherm has been formed in the soil. When crystals in the pores are crystallized, the ice crystals are formed in this cold zone. When the frozen front down there are two situations may arise: on the one hand, in the absence of external water supply conditions, due to continuous growth of ice crystals, pore water in the original position of freezing, soil frozen front to move forward. On the other hand, if the water in the soil migrates upward, the thermal gradient, the interfacial structure of the ice and water, and the surface properties of the soil particles, there is a suitable equilibrium condition. After the ice crystals in the soil, the pore water quickly toward the ice buds and gradually ice formation of ice crystals. During the freezing period, when the cold energy from the surface into the soil and the latent heat released from the pore water and the geothermal phase coming from the unfrozen soil, the frozen fronts are relatively stable at a certain location, The adsorption of ice crystals adsorbs the nearby water molecules to its surface, forming a water film, and the new ice crystals are first produced from here. In this way, the ice crystals on the frozen fronts continue to grow. In order to restore the balance between the adsorption force and the pressure in the water film, it is necessary to pull the water molecules from the adjacent (ie, the soil particles in the non-frozen soil) to replenish the amount of water that is removed.

When the pore water is crystallized and the ice lens body and the ice interlayer are formed near the frozen front, the frost heave of the soil is generated. This is the result of the initial moisture and migration of the soil. It should be noted that the formation of the ice lens on the frozen frontal surface during the freezing process does not constitute the maximum frost heave of the soil alone, and should also include the frost heave of the frozen ice crystals formed by the frozen water in the frozen soil Incremental. In the frozen frontal surface to produce ice volume increases at the same time also produced the expansion of the ice frost heave stress. Therefore, the frost heave of the surface appearance is the amount of frost heave after the completion of the compression of the non-frozen soil. Crystallization process will appear ice crystal "purification" role. The ice crystals formed during the freezing process of the soil have the tendency to repel solutes and other substances, including soil particles and other smallest solid particles. This is the cause of the movement of the soil particles in the frozen interface. As the soil particles are displaced, the ice inter-layers are stacked and stacked to create frost heave. During the formation of the ice lens body, due to soil frost heave displacement, soil pore water generated negative pressure. According to some scholars believe that the cause of frost heave pressure, not all the soil in the water volume increases, but the surface of the soil particles of water film. The low pressure caused by the weakly adsorbed water film is sucked out and the negative pressure caused by crystallization forces the high pressure side of the lower soil particles to migrate toward the negative pressure end of the surface of the soil particles on the frozen frontal surface, so that the frost heave pressure is continuously generated. Once the frozen frontal movement has crossed the ice lens, the frost heave pressure is also reduced or stopped due to the reduction or stop of ice growth. It can be seen that the 
position of the ice lens growth is of great significance to the effect of frost heave pressure.

\section{The Prevention Measures for Prevention and Treatment of Freezing Disaster}

The study of the principle of prevention and control of permafrost, taking soil, water and temperature as the object, observe and analyze the thermodynamic dynamics and the physical and mechanical processes and phenomena in the soil (or foundation) under the positive and negative alternation of atmospheric temperature, The interaction between buildings. The basic control of its processes and phenomena is according to people in advance of the design process to achieve the purpose of frost damage prevention and treatment. Its main developments are:

Natural and human environment under the action of geotechnical structures and the thermal dynamic prediction of the foundation for nearly 30 years, due to the system of permafrost thermodynamics research, the establishment of thermal physics parameters laboratory, and years and seasonal frozen soil roads, houses, The actual observation of the temperature field of water supply, oil pipeline, hydraulic structure and artificial freezing wall has been able to predict the dynamic dynamics of the upper structure and foundation accurately, and provide the basic environmental conditions for solving the freezing injury.

One issue is the most closely related to the cause and prevention of the freezing injury. Over 30 years, the most concerned people in the frozen soil science and technology workers and the cold engineering departments in the country are concerned. The progress will be larger, and direct guidance of the work of the freeze prevention and control work.

Through the indoor experimental study of the system and the large-scale observation work at the scene, the rule of frost heave under different hydrogeological conditions has been mastered, and the critical conditions of ice condensation in cohesive soil are put forward. The ice- And the frost heave sensitivity criterion, and the sufficient conditions for the prevention and cure of frost heaving of fine grained soils. The initial water content, dry bulk density, freezing rate, groundwater level, plasticity index, salinity and The calculation and distribution of the frost heave force during the freezing process are carried out. The results show that the frost heave force is the same as that of the freezing process. The normal frost heave force, the tangential frost heave force and the horizontal frost heave force on the building are put forward. The irreversibility of salt peak temperature and salt swelling is put forward. The effects of different salt, water condition and cooling rate , Penghu and soil complex load on the impact of salt on the law. In recent years, numerical simulation has been applied to the use of computer on the two-dimensional saturated flow problems frozen when the hydrothermal coupling, one-dimensional non-bubble and the subject of hydrothermal coupling and under the load of one-dimensional saturated flow hydrothermal coupling Simulation, to forecast the process of frost heave.

The basic properties of melting and thawing melting - a work mainly combined with permafrost road (including railway), mine construction and Daqing oil field housing shallow buried a large number of field field test study, has initially concluded that frozen soil melting subsidence and And then the compression characteristics under the action of external load. The correlation between melting sinking and compressibility and physical parameters of frozen soil is put forward. In recent years, a numerical model is proposed. These results have been used in the construction of the project to predict the melting deformation of the building, and take appropriate control measures.

Because of the special way of interacting with the foundation of the permafrost and the rheological properties of the ice in the permafrost, the permafrost has a special property of rheological properties (relaxation and creep) compared with the general melt, That is, the strength of frozen soil with temperature, load plus negative speed and duration of instability. On the basis of the experimental study, the relationship between the uniaxial compressive strength and the strain rate and the temperature is proposed. The relationship between the decay and non-decaying creep strain model, the viscous flow velocity and the creep stress is put forward. The tensile strength and shear strength characteristics of permafrost are preliminarily proposed, and the freezing strength between frozen and various base materials is summarized. It provides a basis for solving the problem of permafrost in Qinghai-Tibet railway construction and the calculation and deformation 
prediction of artificial frozen wall.

\section{Conclusion}

In this paper, the distribution of frost damage in cold regions of China, the types and causes of frost damage caused by engineering construction in permafrost regions were briefly discussed. The research progress of prevention and control of frost damage and its prevention and control measures were discussed.

\section{Acknowledgements}

Project: Study on Test and Constitutive Theory of Deformation Characteristics of Silty Sand Considering Rotation of Main Stress Axis

Nature: National Natural Science Foundation of China Youth Project

Project Number: 51409120

\section{References}

[1] Shi Peijun .Study on the theory and practice of disaster system research [J]. Journal of Natural Disasters, 2005 (06)

[2] Yu Shaoshui, Pan Weidong, Shi Conghui, Wang Xiaojun, Liang Bo. An Investigation and Mechanism Analysis of Major Secondary Frozen Soil along Qinghai-Tibet Railway [J] .Chinese Journal of Rock Mechanics and Engineering, 2005 (06)

[3] Wang Shuangjie, Huo Ming, Zhou Wenjin. Qinghai-Tibet Highway permafrost roadbed disease [J]. Highway, 2004 (05)

[4] Meng Fuchu. Study on some problems of disaster, disaster science and disaster research methods [J]. Journal of Natural Disasters, 2002 (04)

[5] Shi Peijun. Three on the theory and practice of disaster research [J]. Journal of Natural Disasters, 2002 (03)

[6] Wu Qingbo, Shi Bin. The Qinghai-Tibet railway construction in the permafrost environmental protection problem [J]. Hydrology and Geology Engineering Geology, 2002 (04) 